\title{
openheart Potential contribution of lifestyle and socioeconomic factors to healthy user bias in antihypertensives and lipid- lowering drugs
}

Mitsuyo Kinjo, ${ }^{1}$ Edward Chia-Cheng Lai, ${ }^{2}$ Maarit Jaana Korhonen, ${ }^{3}$ Rita L McGill, ${ }^{4}$ Soko Setoguchi ${ }^{5}$

To cite: Kinjo M, Chia-Cheng Lai E, Korhonen MJ, et al. Potential contribution of lifestyle and socioeconomic factors to healthy user bias in antihypertensives and lipidlowering drugs. Open Heart 2017;4:e000417. doi:10.1136/ openhrt-2016-000417

- Prepublication history and additional material is available. To view please visit the journal (http://dx.doi.org/10.1136/ openhrt-2016-000417).

Received 01 February 2016 Revised 13 October 2016 Accepted 18 October 2016
CrossMark

For numbered affiliations see end of article.

\section{Correspondence to}

Dr Mitsuyo Kinjo; kinjomitsuyo@ gmail.com

\section{ABSTRACT}

Objectives Healthy user bias arises when users of preventive medications such as lipid-lowering drugs (LLDs), hormone replacement therapy and antihypertensive $(\mathrm{AH})$ medications are healthier than nonusers due to factors other than medication effects, making the medications appear more beneficial in observational studies of effectiveness and safety. The purpose of the study is to examine factors contributing to healthy user effect in patients taking AHs or LLDs.

Methods Among patients with hypertension or hyperlipidaemia in a population-based sample from the National Health and Nutrition Examination Survey (1999-2010), we assessed the association between socioeconomic and lifestyle factors and the use of AHs/LLDs by logistic regression with adjustment for demographics and comorbidities in a cross-sectional study.

Results When $9715 \mathrm{AH} / \mathrm{LLD}$ users were compared with 3725 non-users, AH/LLD users were more likely to be: highly educated (OR $1.2,95 \% \mathrm{Cl} 1.2$ to 1.3 ), nonimpoverished (OR 1.3, 95\% Cl 1.2 to 1.4), current nonsmokers (OR 1.2, 95\% $\mathrm{Cl} 1.1$ to 1.4), physically active (OR $1.1,95 \% \mathrm{Cl} 1.0$ to 1.2 ) and consume more calcium (OR $1.1,95 \% \mathrm{Cl} 1.0$ to 1.3$)$ but less likely to have normal body mass index (OR $0.6,95 \% \mathrm{Cl} 0.6$ to 0.7 ) or to meet dietary sodium recommendations (OR $0.8,95 \% \mathrm{Cl} 0.7$ to 0.9 ). Conclusions We identified several salutary lifestyle factors associated with AH/LLD use in a representative US population. Healthy user effect may be partly explained by better socioeconomic profiles and lifestyles in AH/LLD users compared with non-users.

\section{INTRODUCTION}

Antihypertensive (AH) and lipid-lowering drugs (LLDs) are widely used for the prevention of cardiovascular disease. ${ }^{1-3}$ Demographic and socioeconomic factors may influence the use of AHs/LLDs, as well as comorbid conditions, health behaviours and prescriber characteristics. ${ }^{4-7}$ For example, patients with diabetes and cardiovascular disease may be motivated to take AHs/LLDs, but preventive therapy for asymptomatic hypertension and hyperlipidaemia may be prescribed less often

\section{KEY QUESTIONS}

What is already known about this subject?

- Healthy user bias arises when users of preventive medications are healthier due to factors other than medication effects. Cardiovascular event reduction is consistently smaller in clinical trials compared with observational studies of antihypertensives (AHs) or lipid-lowering drugs (LLDs).

What does this study add?

- We identified several salutary lifestyle factors associated with AH/LLD use. Healthy user effect may be partly explained by better socioeconomic profiles and lifestyles in AH/LLD users compared with non-users. Further, AH/LLD users tend not to follow some healthy dietary guidelines such as fat intake as they may obviate the need for dietary modification.

How might this impact on clinical practice?

- It helps us understand the healthy user bias that distorts observational studies of $A H / L L D$ effectiveness.

for a frail elderly patient with many comorbid conditions.

Healthy user bias arises when users of preventive medications such as AHs/LLDs or hormone replacement therapy are healthier due to factors other than medication effects. Cardiovascular event reduction is consistently smaller in clinical trials compared with observational studies of AHs/LLDs,${ }^{8} 9$ which suggests healthy user bias may interfere with observational studies of preventive therapies. Also, AH non-adherence can increase the risk of cardiovascular disease and death irrespective of blood pressure (BP) control. ${ }^{10}$ Healthy user bias may be refractory to analytic solutions, unless prevented by thoughtful study design, resulting in inflation of the benefits of preventive medications. We recently described a similar bias that compromised 
the ability to assess the effectiveness of implantable devices using clinical and administrative data. ${ }^{11}$

Despite the serious potential impact, factors that contribute to healthy user effects in preventive therapies are not well described. Patients who adhere to preventive medications may be more amenable to healthy diets, regular exercise and healthcare screening and less prone to using tobacco or alcohol. In one study, patients who were adherent to statin therapy were more likely than those who were non-adherent to have cancer screening and vaccinations. ${ }^{12}$ Dietary, lifestyle and socioeconomic factors all affect cardiovascular mortality in users and non-users of AHs/LLDs. ${ }^{13-15}$ This cross-sectional study seeks to understand how dietary, socioeconomic and lifestyle factors contribute to healthy user bias among patients with hypertension and hyperlipidaemia, using representative samples from the National Health and Nutrition Examination Survey (NHANES) from 1999 to 2010.

\section{METHODS}

\section{Data source and study population}

Cross-sectional surveys conducted by the National Center for Health Statistics of the Centers for Disease Control in NHANES 1999-2000, 2001-2002, 2003-2004, 2005-2006, 2007-2008 and 2009-2010 provided survey data representing the civilian, non-institutionalized population in the USA. A multistage, stratified sampling design was used; participants were interviewed first, and then invited to an examination centre. NHANES 1999-2010 included self-reported hypertension and hyperlipidaemia, and monitored prescription use, among 62161 adults who consented to participate. NHANES was approved by the review committee of the National Center for Health Statistics.

\section{Hypertension cohort: indications and the use of AHs}

Among subjects with self-reported hypertension, we identified who answered 'yes' to the question: "Because of your high $\mathrm{BP} /$ hypertension, have you ever been told to take prescribed medicine?" These subjects were also asked if they were currently taking prescribed medication. Those who answered 'yes' were considered AH users. Mean BP measurements were assessed for those who responded 'no.' The need for treatment was identified using criteria of the Joint National Committee: subjects with systolic BP $\geq 140 \mathrm{~mm} \mathrm{Hg}$ or diastolic BP $\geq 90 \mathrm{~mm} \mathrm{Hg}$ were classified as non-users of AHs. ${ }^{16}$ We analysed self-reported prescription $\mathrm{AH}$ users in our primary analyses.

\section{Hyperlipidaemia cohort}

We identified subjects with indications for primary or secondary prevention with LLDs. We identified all subjects with self-reported hyperlipidaemia who answered yes to the question: "To lower your blood cholesterol, have you ever been told by a doctor or other health professional to take prescribed medicine?" These subjects were asked if they were currently taking prescribed lipid-lowering medication (statins and non-statins). Those who answered 'yes' to this question were categorised as LLD users; all others were categorised as non-users, including subjects with indications for secondary prevention with LLDs, including: self-reported coronary artery disease (CAD), myocardial infarction, angina pectoris, cerebrovascular disease and coronary heart disease (CHD) risk equivalents (eg, diabetes). ${ }^{17}$

\section{Medication use and comparison groups}

In the primary analysis, we compared $\mathrm{AH}$ users versus non-users without detailed prescription information. Some AH users were also LLD users and vice versa. We then combined all medication users (AH, LLD user or both) and compared them with non-users.

The mean age of the population in the study was 62.2 (age range 20-85) years old, and the proportion of women was $50.7 \%$.

\section{Lifestyle and socioeconomic factors potentially related to healthy user effect}

Body mass index (BMI) was calculated from measured weight and height ${ }^{18}$ and dichotomised as $<25$ versus $>25$ $\mathrm{kg} / \mathrm{m}^{2}$. Physical activity was assessed by calculating metabolic equivalents of task (METs), using the responses to a previously validated NHANES Activity Questionnaire. ${ }^{19}$ Subjects were categorised as pursuing moderate exercise ( $>3$ METs for $>150 \mathrm{~min} /$ week) versus less activity. Cigarette smoking was assessed by a question: "Do you smoke cigarettes now?" Subjects were classified as former/never versus current. Alcohol consumption was categorised as moderate use (<five drinks per week) and categories included: none, moderate and more than moderate. Multivitamin use was assessed as a yes/no question. Self-reported health status in five grades was dichotomised as either 'excellent/very good' versus all other categories.

Socioeconomic factors included the poverty-to-income ratio, a ratio of the observed family income and the annual US Census poverty threshold ( $>1$ vs $<1$ ). Educational level was assessed as $>12$ years versus $<12$ years. Self-reported comorbid conditions included: diabetes, heart disease (angina or congestive heart failure), cerebrovascular disease, chronic obstructive pulmonary disease (COPD), non-skin cancers and arthritis.

\section{Dietary variables}

Dietary patterns of food and beverages were ascertained through two 24-hour dietary recalls, one in-person interview followed by another by telephone using dietary data collection instrument of the US Department of Agriculture. Both weekdays and weekends were sampled. Second dietary recall interview was conducted 3-7 days after the first interview. The dietary data were analysed via the US Department of Agriculture's Automated Multiple Pass Method and were compared with Dietary Approach to Stop Hypertension (DASH) recommendations. Nutrients assessed for DASH compliance included: total fat, saturated fat, protein, cholesterol, fibre, magnesium, calcium, sodium and potassium. In order to calculate DASH score, continuous variables for protein, saturated fat and total fat 
Table 1 Demographic, social, health and lifestyle characteristics by medication use among patients with hypertension or hyperlipidaemia who were recommended/indicated for pharmacological treatments

\begin{tabular}{|c|c|c|c|c|}
\hline & $\begin{array}{l}\text { Hypertensive subjects } \\
\text { on antihypertensives } \\
\text { (AHs) }\end{array}$ & $\begin{array}{l}\text { Hypertensive } \\
\text { subjects } \\
\text { without AHs }\end{array}$ & $\begin{array}{l}\text { Hyperlipidaemic } \\
\text { subjects on lipid- } \\
\text { lowering medications }\end{array}$ & $\begin{array}{l}\text { Hyperlipidaemic } \\
\text { subjects without } \\
\text { lipid-lowering } \\
\text { medications }\end{array}$ \\
\hline $\mathbf{N}$ & 8099 & 3752 & 4645 & 4550 \\
\hline Age, mean (SD) & $65.9(13.1)^{*}$ & $49.8(17.2)$ & $64.9(12.2)^{*}$ & $63.1(15.4)$ \\
\hline Gender ( $\%$ female) & $4438(54.8)^{*}$ & $1751(46.7)$ & $485(48.7)^{*}$ & $2257(49.6)$ \\
\hline \multicolumn{5}{|l|}{ Race (\%) } \\
\hline Non-Hispanic white & $4214(52.0)^{*}$ & $1820(48.5)$ & $2684(57.8)^{*}$ & $2219(48.8)$ \\
\hline Non-Hispanic black & $2079(25.7)$ & $805(21.5)$ & $837(18.0)$ & $998(21.9)$ \\
\hline Mexican American & $1111(13.7)$ & $780(20.8)$ & $681(14.7)$ & $891(19.6)$ \\
\hline Education >12 years (\%) & $2132(60.9)^{*}$ & $1450(38.8)$ & $640(64.5)^{*}$ & $1220(54.2)$ \\
\hline Non-impoverished (\%) & $6040(82.3)^{*}$ & $2756(80.6)$ & $3583(84.9)$ & $3170(77.4)$ \\
\hline Non-current smoker (\%) & $6923(85.5)$ & $791(21.1)$ & $666(14.3)^{\star}$ & $866(19.0)$ \\
\hline $\begin{array}{l}\text { Reported health, Excellent/ } \\
\text { very good (\%) }\end{array}$ & $2039(25.2)^{*}$ & $1463(39.0)$ & $1231(26.5)^{\star}$ & $950(20.9)$ \\
\hline Alcohol <5 drinks (\%) & $7003(86.5)^{\star}$ & $848(84.1)$ & $693(14.9)$ & $3850(84.6)$ \\
\hline Body mass index, mean (SD) & $30.9(7.0)$ & $30.0(7.1)$ & $30.2(6.3)$ & $30.1(7.0)$ \\
\hline$\geq 30.0$ & $3529(43.6)$ & $1337(35.6)$ & $1927(41.5)$ & $1719(37.8)$ \\
\hline $25.0-29.9$ & 2466 (30.5) & $1307(34.8)$ & $1553(33.4)$ & $1382(30.4)$ \\
\hline$<25.0$ & $2104(26.9)$ & $1108(29.5)$ & $1165(25.1)$ & $1449(31.8)$ \\
\hline $\begin{array}{l}\text { Physical activity } \\
>150 \mathrm{~min} / \text { week (\%) }\end{array}$ & $1157(14.3)$ & $624(16.7)$ & $752(16.3)$ & $740(16.3)$ \\
\hline Multivitamin use (\%) & 2665 (32.9) & $1205(32.1)$ & $1636(35.2)$ & $1322(29.1)$ \\
\hline Hyperlipidaemia & $993(12.3)^{*}$ & $381(10.2)$ & & \\
\hline Hypertension & & & $3200(68.9)^{\star}$ & 2621 (57.6) \\
\hline Diabetes & $2137(26.4)^{*}$ & $372(9.9)$ & $1404(30.2)^{*}$ & $2123(46.7)$ \\
\hline Heart disease & $1756(21.7)^{\star}$ & $344(9.2)$ & $1230(26.5)^{\star}$ & $1703(37.4)$ \\
\hline Cerebrovascular & $796(9.8)^{\star}$ & $143(3.8)$ & $414(8.9)^{\star}$ & $823(18.1)$ \\
\hline $\begin{array}{l}\text { Chronic obstructive } \\
\text { pulmonary disease }\end{array}$ & $875(10.8)$ & $292(7.8)$ & $515(11.1)$ & $568(12.5)$ \\
\hline Non-skin cancer & $1323(16.3)^{*}$ & $381(10.2)$ & $764(16.5)^{\star}$ & 705 (15.5) \\
\hline Arthritis & $3914(48.3)^{*}$ & 1119 (29.8) & $2245(48.3)^{\star}$ & \\
\hline Dietary variables & $N=4484$ & $N=1799$ & $N=2875$ & $N=2267$ \\
\hline DASH score $>4.5$ & 799 (17.8) & $289(16.1)$ & 514 (17.9) & $403(17.8)$ \\
\hline Total fat & $1001(23.3)^{*}$ & 496 (27.6) & $673(23.4)$ & $514(22.7)$ \\
\hline Saturated fat & $410(9.1)$ & $210(11.7)$ & $253(8.8)$ & $230(10.6)$ \\
\hline Protein & 1335 (29.8) & $452(25.1)$ & $866(30.1)$ & 708 (31.2) \\
\hline Fibre & $434(9.7)^{\star}$ & 155 (8.6) & $262(9.1)$ & $215(9.5)$ \\
\hline Cholesterol & $478(34.4)^{\star}$ & $400(22.2)$ & $596(20.7)$ & $461(20.3)$ \\
\hline Calcium & 2418 (53.9) & $948(52.7)$ & $1573(54.7)$ & 1177 (51.9) \\
\hline Magnesium & $262(5.8)^{\star}$ & $84(4.7)$ & $164(5.7)^{\star}$ & $124(5.5)$ \\
\hline Potassium & $258(5.8)^{\star}$ & $76(4.2)$ & $162(5.6)^{\star}$ & $326(14.4)$ \\
\hline Sodium & $600(13.4)^{*}$ & $331(18.4)$ & $362(12.6)^{\star}$ & $326(14.4)$ \\
\hline
\end{tabular}

${ }^{*} \mathrm{p}<0.05$.

DASH, Dietary Approach to Stop Hypertension. 
Table 2 Association between each demographic and healthy lifestyle factor and the use of medications among subjects with hypertension recommended/indicated pharmacological treatments ( $N=11$ 851): OR was calculated comparing antihypertensive users versus non-users*

\begin{tabular}{|c|c|c|c|c|}
\hline Demographic and healthy lifestyle factors & Unadjusted OR $(95 \% \mathrm{Cl})^{\dagger}$ & $\mathrm{p}$ Value & Adjusted OR $(95 \% \mathrm{Cl})^{\dagger}$ & p Value \\
\hline Education $>12$ years & $1.0(0.9$ to 1.1$)$ & 0.8 & $1.3(1.2$ to 1.4$)$ & $<0.0001$ \\
\hline Non-impoverished & 1.1 (1.0 to 1.2$)$ & 0.03 & $1.3(1.1$ to 1.4$)$ & 0.0004 \\
\hline Smoking, Not current & $1.5(1.4$ to 1.7$)$ & $<0.0001$ & $1.2(1.1$ to 1.3$)$ & 0.002 \\
\hline Alcohol $<5$ drinks/week & $1.2(1.1$ to 1.3$)$ & 0.0006 & 1.1 (1.0 to 1.2$)$ & 0.1 \\
\hline Body mass index $<25$ & $0.8(0.8$ to 0.9$)$ & $<0.0001$ & 0.7 (0.6 to 0.8$)$ & $<0.0001$ \\
\hline Physical activity $>150 \mathrm{~min} /$ week & $0.8(0.7$ to 0.9$)$ & 0.0007 & $1.0(0.9$ to 1.1$)$ & 0.7 \\
\hline Reported health, Excellent/very good & 0.5 (0.5 to 0.6$)$ & $<0.0001$ & $0.7(0.6$ to 0.8$)$ & $<0.0001$ \\
\hline Multivitamin use & $1.0(1.0$ to 1.1$)$ & 0.4 & $1.0(0.9$ to 1.1$)$ & 0.6 \\
\hline \multicolumn{5}{|l|}{ Dietary variables } \\
\hline DASH accordance & $1.1(1.0$ to 1.3$)$ & 0.07 & $1.0(0.9$ to 1.1$)$ & 0.7 \\
\hline Total fat & $0.9(0.8$ to 1.0$)$ & 0.008 & $0.9(0.8$ to 1.0$)$ & 0.02 \\
\hline Saturated fat & $0.9(0.8$ to 1.0$)$ & 0.1 & 0.9 (0.9 to 1.0$)$ & 0.2 \\
\hline Protein & $1.2(1.1$ to 1.3$)$ & 0.003 & $1.1(1.0$ to 1.3$)$ & 0.01 \\
\hline Fibre & $1.3(1.2$ to 1.4$)$ & $<0.0001$ & $1.0(0.9$ to 1.1$)$ & 0.9 \\
\hline Cholesterol & 0.9 (0.8 to 1.0$)$ & 0.02 & $0.9(0.8$ to 1.0$)$ & 0.01 \\
\hline Calcium & $1.0(0.9$ to 1.1$)$ & 0.6 & 1.2 (1.0 to 1.3$)$ & 0.03 \\
\hline Magnesium & $1.4(1.2$ to 1.5$)$ & $<0.0001$ & 1.3 (1.1 to 1.6$)$ & 0.009 \\
\hline Potassium & 1.4 (1.3 to 1.6$)$ & $<0.0001$ & 1.1 (1.0 to 1.2$)$ & 0.2 \\
\hline Sodium & 0.7 (0.6 to 0.8$)$ & $<0.0001$ & $0.8(0.7$ to 0.9$)$ & 0.0008 \\
\hline
\end{tabular}

*8099 antihypertensive users versus 3752 non-users.

${ }^{\dagger}$ Adjusted for age, gender, race, diabetes, cardiovascular disease (angina, congestive heart failure and cerebrovascular disease) and other comorbid conditions (cancer, arthritis and chronic obstructive pulmonary disease).

DASH, Dietary Approach to Stop Hypertension.

as a percentage of total energy were developed. For cholesterol, fibre, magnesium, calcium, potassium and sodium intake per 1000 calories was computed. Binary variables were constructed to indicate whether the target intake for each nutrient was met in each study subject, based on the intermediate DASH and DASH classifications. A DASH score of $0-9$ was calculated as the number of nutrient targets met (see online supplementary table), with achievement of each DASH nutrient goal earning a score of 1 . Nutrient intakes that exceeded the DASH control diet but did not meet DASH goals earned 0.5 points. Total DASH score $>4.5$ defined DASH adherence. ${ }^{20}$

\section{Statistical analysis}

Differences between subjects taking AHs or LLDs and non-users were tested with a Student's t-test for continuous variables and Pearson's $\chi^{2}$ test for categorical variables. We used logistic regression to estimate unadjusted and adjusted ORs for associations between dependent (dietary, lifestyle and socioeconomic) variables, with the use of AHs or LLDs as an independent variable. Some values were missing for lifestyle factors and comorbidities. We handled missing values by using multiple imputation and assuming an underlying multivariate normal distribution. We presented point estimates and $95 \%$ CIs for unadjusted and adjusted ORs, including comorbid conditions, as described. In the primary analysis, we defined users and non-users by self-reported medication use and conducted separate analyses in the hypertension and hyperlipidaemia cohorts. We then combined the hypertension and hyperlipidaemia cohorts to assess the general association between healthy lifestyle factors and the use of any preventive medications. We used multivariable logistic models controlling for age, gender, race and comorbid conditions (including history of diabetes, heart disease, COPD, cancer and arthritis) to compute adjusted ORs.

\section{Sensitivity analyses}

A sensitivity analysis was conducted after excluding subjects with indications for LLDs as secondary prevention to assess the impact of patients with known disease. As the number of self-reported medication users exceeded the number of confirmed prescription users, we assessed the impact of misclassification on drug use by restricting AH or LLD use to patients for whom NHANES interviewers verified prescription use by examining medication containers. We compared 'verified' prescription AH or LLD users versus non-users. AHs included betablockers, thiazides, calcium channel blockers, ACE-I or 
Table 3 Association between each healthy lifestyle factor and the use of medications among subjects with hyperlipidaemia recommended/indicated pharmacological treatments ( $\mathrm{N}=9195)$ : OR was calculated comparing lipid-lowering drug users versus non-users*

\begin{tabular}{|c|c|c|c|c|}
\hline Demographic and healthy lifestyle factors & Unadjusted OR $(95 \% \mathrm{Cl})$ & p Value & Adjusted OR $(95 \% \mathrm{Cl})^{\dagger}$ & p Value \\
\hline Education $>12$ years & $1.3(1.2$ to 1.4$)$ & $<0.0001$ & $1.2(1.0$ to 1.4$)$ & 0.001 \\
\hline Non-impoverished & $1.6(1.5$ to 1.8$)$ & $<0.0001$ & $1.3(1.2$ to 1.5$)$ & $<0.0001$ \\
\hline Smoking, Not current & $1.4(1.3$ to 1.6$)$ & $<0.0001$ & $1.2(1.1$ to 1.3$)$ & 0.001 \\
\hline Alcohol $<5$ drinks & $1.0(0.9$ to 1.2$)$ & 0.5 & $1.0(0.8$ to 1.1$)$ & 0.5 \\
\hline Body mass index $<25$ & 0.7 (0.7 to 0.8$)$ & $<0.0001$ & 0.7 (0.7 to 0.8$)$ & $<0.0001$ \\
\hline Physical activity >150 min/week & $1.3(1.2$ to 1.5$)$ & $<0.0001$ & $1.3(1.1$ to 1.4$)$ & 0.0002 \\
\hline Reported health, excellent/very good & $1.3(1.2$ to 1.5$)$ & $<0.0001$ & $1.0(0.9$ to 1.1$)$ & 0.5 \\
\hline Multivitamin use & $1.3(1.2$ to 1.5$)$ & $<0.0001$ & $1.2(1.1$ to 1.3$)$ & 0.001 \\
\hline \multicolumn{5}{|l|}{ Dietary variables } \\
\hline DASH accordance & 1.0 (0.9 to 1.2$)$ & 0.9 & $1.0(0.8$ to 1.1$)$ & 0.9 \\
\hline Total fat & 1.0 (0.9 to 1.1$)$ & 0.7 & $1.0(0.9$ to 1.1$)$ & 0.9 \\
\hline Saturated fat & 0.9 (0.8 to 1.0$)$ & 0.1 & 1.0 (0.8 to 1.2$)$ & 0.8 \\
\hline Protein & 0.9 (0.8 to 1.0$)$ & 0.2 & 0.9 (0.8 to 1.0$)$ & 0.05 \\
\hline Fibre & 1.0 (0.9 to 1.2$)$ & 0.6 & 1.0 (0.9 to 1.1$)$ & 0.5 \\
\hline Cholesterol & 1.1 (0.9 to 1.2$)$ & 0.4 & $1.0(0.9$ to 1.1$)$ & 0.9 \\
\hline Calcium & 1.2 (1.0 to 1.3$)$ & 0.008 & 1.2 (1.1 to 1.3$)$ & 0.03 \\
\hline Magnesium & 1.0 (0.9 to 1.2$)$ & 0.5 & 1.0 (0.9 to 1.1$)$ & 0.9 \\
\hline Potassium & 1.1 (0.9 to 1.2$)$ & 0.4 & 1.0 (0.9 to 1.2$)$ & 0.7 \\
\hline Sodium & $0.9(0.8$ to 1.0$)$ & 0.1 & $0.9(0.8$ to 1.0$)$ & 0.03 \\
\hline
\end{tabular}

*4645 LLD users versus 4550 non-users.

${ }^{\dagger}$ Adjusted for age, gender, race, diabetes, cardiovascular disease (angina, congestive heart failure and cerebrovascular disease) and other comorbid conditions (cancer, arthritis and chronic obstructive pulmonary disease).

DASH, Dietary Approach to Stop Hypertension.

angiotensin receptor blockers (ARBs). LLDs included statins and non-statins.

All analyses were conducted using SAS (V.9, Cary, North Carolina, USA).

\section{RESULTS}

In NHANES 1999-2010, 14856 subjects reported either hypertension or hyperlipidaemia. Our criteria yielded a final hypertension cohort of 11851 subjects. The primary/ secondary LLD cohort had 9195 subjects, defined as those being advised by a doctor to take LLDs or having an indication for primary or secondary prevention.

Among 11851 hypertensive subjects, there were 8099 $\mathrm{AH}$ users and 3752 non-users. Compared with non-users, $\mathrm{AH}$ users had higher mean age (66 vs 50 years) and were more often: women, Caucasian, former/never smokers or overweight. $\mathrm{AH}$ users were highly educated and more likely to report incomes above the poverty level. AH users reported worse health and more comorbid conditions and were more likely to meet DASH dietary components except for sodium intake (all p<0.05) (table 1). After adjustment for age, gender, race and comorbid conditions, AH users had higher odds of: being more educated (OR 1.3, 95\% CI 1.2 to 1.4); having more income (OR $1.3,95 \%$ CI 1.1 to 1.4 ) and being non-current smokers
(OR 1.2, 95\% CI 1.1 to 1.4 ). AH users had reduced odds of: having normal weight (OR $0.7,95 \%$ CI 0.6 to 0.8 ) or self-reporting health as excellent or good (OR 0.7, 95\% CI 0.6 to 0.8$)$. AH users had higher intakes of total fat, cholesterol, protein, calcium, magnesium and sodium (table 2).

Among 9195 subjects with hyperlipidaemia, 4645 LLD users and 4550 non-users were identified. LLD users were more likely to be: Caucasian, better educated, non-current smokers, physically active and use multivitamins. LLD users reported less cardiovascular disease, but more hypertension (all $\mathrm{p}<0.05$ ) (table 1 ). After adjustment for age, gender, race and comorbid conditions, prevalent LLD users were more likely to be: highly educated (OR $1.2,95 \%$ CI 1.0 to 1.4 ), current non-smokers (OR 1.2, 95\% CI 1.1 to 1.3 ), more physically active (OR $1.3,95 \%$ CI 1.1 to 1.4 ) and use more multivitamins (OR 1.2, 95\% CI 1.1 to 1.3 ), but less likely to have $\mathrm{BMI}<25$ (OR 0.7 , $95 \%$ CI 0.7 to 0.8 ) or to report good/excellent health (OR $0.8,95 \%$ CI 0.7 to 0.9 ). Overall DASH scores were not different between users and non-users, although users had higher intakes of magnesium and calcium. A trend towards higher intake of sodium in users was also seen (table 3).

Both conditions were simultaneously reported in 6190 subjects for a combined cohort of 14856 subjects 
Table 4 Association between each demographic or healthy lifestyle factor and the use of medications among subjects with hypertension or hyperlipidaemia recommended/indicated pharmacological treatments ( $N=14$ 856): OR was calculated comparing antihypertensive and lipid-lowering drug users versus non-users ${ }^{\star}$

\begin{tabular}{|c|c|c|c|c|}
\hline Demographic and healthy lifestyle factors & Adjusted OR (95\% Cl) & p Value & Adjusted OR $(95 \% \mathrm{Cl})^{\dagger}$ & p Value \\
\hline Education $>12$ years & 1.1 (1.0 to 1.2$)$ & 0.03 & $1.2(1.2$ to 1.3$)$ & $<0.0001$ \\
\hline Above poverty-to-income ratio & $1.3(1.2$ to 1.5$)$ & $<0.0001$ & $1.3(1.2$ to 1.4$)$ & $<0.0001$ \\
\hline Smoking, Not current & $1.7(1.5$ to 1.8$)$ & $<0.0001$ & $1.2(1.1$ to 1.4$)$ & $<0.0001$ \\
\hline Alcohol $<5$ drinks & $1.2(1.1$ to 1.4$)$ & $<0.0001$ & $1.0(0.9$ to 1.2$)$ & 0.4 \\
\hline Body mass index $<25$ & 0.7 (0.7 to 0.8$)$ & $<0.0001$ & 0.6 (0.6 to 0.7$)$ & $<0.0001$ \\
\hline Moderate physical activity $>150 \mathrm{~min} /$ week & $1.0(1.2$ to 1.5$)$ & 0.3 & 1.1 (1.0 to 1.2$)$ & 0.04 \\
\hline Self-reported health, Excellent or very good & 0.7 (0.6 to 0.7$)$ & $<0.0001$ & $0.7(0.6$ to 0.8$)$ & $<0.0001$ \\
\hline Multivitamin use & 1.1 (1.1 to 1.2$)$ & 0.001 & 1.0 (0.9 to 1.1$)$ & 0.9 \\
\hline \multicolumn{5}{|l|}{ Dietary variables } \\
\hline DASH accordance & 1.0 (0.9 to 1.2$)$ & 0.9 & $1.0(0.8$ to 1.1$)$ & 0.9 \\
\hline Total fat & $1.0(0.9$ to 1.1$)$ & 0.7 & $1.0(0.9$ to 1.1$)$ & 0.9 \\
\hline Saturated fat & 0.9 (0.8 to 1.0$)$ & 0.1 & 1.0 (0.8 to 1.2 ) & 0.8 \\
\hline Protein & 0.9 (0.8 to 1.0$)$ & 0.2 & 0.9 (0.8 to 1.0$)$ & 0.05 \\
\hline Fibre & 1.0 (0.9 to 1.2$)$ & 0.6 & 1.0 (0.9 to 1.1$)$ & 0.5 \\
\hline Cholesterol & 1.1 (0.9 to 1.2$)$ & 0.4 & $1.0(0.9$ to 1.1$)$ & 0.9 \\
\hline Calcium & 1.1 (1.0 to 1.2$)$ & 0.2 & 1.1 (1.0 to 1.3$)$ & 0.007 \\
\hline Magnesium & 1.2 (1.1 to 1.2$)$ & $<0.0001$ & 1.0 (0.9 to 1.2$)$ & 0.4 \\
\hline Potassium & 1.3 (1.2 to 1.5$)$ & $<0.0001$ & $1.0(0.9$ to 1.1$)$ & 0.6 \\
\hline Sodium & 0.7 (0.7 to 0.8$)$ & $<0.0001$ & 0.8 (0.7 to 0.9$)$ & $<0.0001$ \\
\hline
\end{tabular}

*9715 antihypertensive/lipid-lowering drug users versus 3725 non-users.

${ }^{\dagger}$ Adjusted for age, gender, race, diabetes, cardiovascular disease (angina, congestive heart failure and cerebrovascular disease) and other comorbid conditions (cancer, arthritis and chronic obstructive pulmonary disease).

DASH, Dietary Approach to Stop Hypertension.

(11 851 patients with hypertension and 9195 with hyperlipidaemia). In the secondary analysis, we compared 3725 patients who reported neither AH nor LLD use with 9715 who were using one or both types of medication. Lifestyle factors in the combined cohort of medication users resembled that of AH users (table 4). When we analyse results by gender and age, male or younger AH/LLD users tended not to follow DASH recommendation, especially fat intake (data not shown).

\section{Sensitivity analyses}

For sensitivity analyses, we excluded all subjects who have a secondary prevention indication for LLDs. The distribution of socioeconomic, lifestyle and dietary factors remained similar to the main analysis.

We also compared verified users of prescription medications with non-users in subjects with hypertension and hyperlipidaemia (tables 5 and 6). In this model, we compared 4451 subjects using AH agents with 7400 as AH non-users. In the primary/secondary LLD cohort, 2122 were users and 7073 were non-users. The healthy lifestyle factors in $\mathrm{AH}$ users were similar to the unadjusted data, except that the exposure OR of increased physical activity in AH users became statistically significant. After adjustment, the associations of self-reported health and multivitamin use were no longer satistitcally significant between LLD users and non-users.

\section{DISCUSSION}

These data show that healthier lifestyles and more favourable socioeconomic conditions were positively associated with AH/LLD use. AH users had higher levels of income and education and were more likely to be non-smokers. LLD users were physically more active than non-users, but both AH or LLD users were more frequently overweight and consumed more sodium than non-users.

The relationships between economic factors and adherence have been well described. Insufficient income may promote non-adherence to expensive prescriptions, so higher incomes in $\mathrm{AH}$ users could have contributed to better adherence. A Canadian study showed that prescription non-adherence increased as income levels decreased. ${ }^{21}$ A Danish study showed that after myocardial infarction, impoverished patients were less likely to initiate statin therapy than those with higher incomes. ${ }^{22}$ Education level may also promote the use of AHs, because increased awareness of the benefits of BP control may provide motivation for adherence. Higher educational 
Table 5 Association between each demographic or healthy lifestyle factor and the use of verified medications among subjects with hypertension recommended/indicated pharmacological treatments ( $\mathrm{N}=11$ 851): OR was calculated comparing antihypertensive users versus non-users

\begin{tabular}{lll}
\hline $\begin{array}{l}\text { Demographic or healthy } \\
\text { lifestyle factors }\end{array}$ & $\begin{array}{l}\text { Adjusted OR } \\
(\mathbf{9 5 \%} \mathbf{C l})^{\ddagger}\end{array}$ & p Value \\
\hline Education >12 years & $1.2(1.1$ to 1.3$)$ & 0.0001 \\
\hline $\begin{array}{l}\text { Non-impoverished } \\
\text { Smoking, Not current }\end{array}$ & $1.2(1.0$ to 1.3$)$ & 0.006 \\
\hline Alcohol <5 drinks & $1.0(0.9$ to 1.1$)$ & 0.8 \\
\hline Body mass index $<25$ & $0.7(0.6$ to 0.8$)$ & $<0.0001$ \\
\hline $\begin{array}{l}\text { Moderate physical activity } \\
\text { >150 min/week }\end{array}$ & $1.2(1.0$ to 1.3$)$ & 0.006 \\
\hline $\begin{array}{l}\text { Reported health, } \\
\text { Excellent/very good }\end{array}$ & $0.8(0.7$ to 0.9$)$ & $<0.0001$ \\
\hline Multivitamin use & $1.1(1.0$ to 1.2$)$ & 0.2 \\
\hline Dietary variables & & \\
\hline DASH accordance & $0.9(0.8$ to 1.1$)$ & 0.3 \\
\hline Total fat & $0.9(0.8$ to 1.0$)$ & 0.01 \\
\hline Saturated fat & $1.0(0.9$ to 1.1$)$ & 0.4 \\
\hline Protein & $1.0(0.9$ to 1.1$)$ & 0.5 \\
\hline Fibre & $1.0(0.9$ to 1.1$)$ & 0.6 \\
\hline Cholesterol & $1.0(0.9$ to 1.1$)$ & 0.4 \\
\hline Calcium & $1.1(1.0$ to 1.2$)$ & 0.04 \\
\hline Magnesium & $1.1(0.9$ to 1.2$)$ & 0.4 \\
\hline Potassium & $1.0(0.9$ to 1.1$)$ & 0.8 \\
\hline Sodium & $0.9(0.8$ to 1.0$)$ & 0.02 \\
\hline & & \\
\hline
\end{tabular}

*Users of beta-blockers, thiazide, calcium channel blockers, ACE-I, ARB or any combination of these medications.

${ }^{\dagger} 4451 \mathrm{AH}$ users versus 7400 non-users.

${ }^{\ddagger}$ Adjusted for age, gender, race, diabetes, cardiovascular disease (angina, congestive heart failure and cerebrovascular disease) and other comorbid conditions (cancer, arthritis and chronic obstructive pulmonary disease).
Table 6 Association between each demographic or healthy lifestyle factor and the use of verified medications among subjects with hyperlipidaemia recommended/indicated pharmacological treatments $(\mathrm{N}=9195)$ : OR was calculated comparing lipid-lowering drug users versus non-users*

\begin{tabular}{|c|c|c|}
\hline $\begin{array}{l}\text { Demographic or healthy } \\
\text { lifestyle factors }\end{array}$ & $\begin{array}{l}\text { Adjusted OR } \\
(95 \% \mathrm{Cl})^{\ddagger}\end{array}$ & p Value \\
\hline Education $>12$ years & 1.1 (1.0 to 1.2$)$ & 0.3 \\
\hline Non-impoverished & 1.1 (1.0 to 1.3$)$ & 0.06 \\
\hline Smoking, Not current & 1.0 (0.9 to 1.1$)$ & 0.9 \\
\hline Alcohol $<5$ drinks & 0.9 (0.8 to 1.0$)$ & 0.04 \\
\hline Body mass index $<25$ & 0.7 (0.7 to 0.8$)$ & $<0.0001$ \\
\hline $\begin{array}{l}\text { Physical activity } \\
>150 \mathrm{~min} / \text { week }\end{array}$ & $1.3(1.1$ to 1.5$)$ & $<0.0001$ \\
\hline $\begin{array}{l}\text { Reported health, } \\
\text { Excellent/very good }\end{array}$ & $1.0(0.9$ to 1.1$)$ & 0.7 \\
\hline Multivitamin use & $1.0(0.9$ to 1.1$)$ & 1 \\
\hline \multicolumn{3}{|l|}{ Dietary variables } \\
\hline DASH accordance & $1.0(0.8$ to 1.1$)$ & 0.8 \\
\hline Total fat & 1.0 (0.9 to 1.2$)$ & 0.4 \\
\hline Saturated fat & $0.9(0.8$ to 1.1$)$ & 0.4 \\
\hline Protein & 1.1 (0.9 to 1.2$)$ & 0.3 \\
\hline Fibre & $1.0(0.9$ to 1.1$)$ & 0.9 \\
\hline Cholesterol & $1.0(0.9$ to 1.1$)$ & 0.7 \\
\hline Calcium & 1.1 (0.9 to 1.2$)$ & 0.3 \\
\hline Magnesium & 1.1 (1.0 to 1.2$)$ & 0.2 \\
\hline Potassium & 1.1 (0.9 to 1.3$)$ & 0.1 \\
\hline Sodium & 0.9 (0.7 to 1.0$)$ & 0.02 \\
\hline
\end{tabular}

*Users of statins or non-statin lipid-lowering agents. †2122 LLD users and 7077 non-users.

¥Adjusted for age, gender, race, diabetes, cardiovascular disease (angina, congestive heart failure and cerebrovascular disease) and other comorbid conditions (cancer, arthritis and chronic obstructive pulmonary disease).

DASH, Dietary Approach to Stop Hypertension.

scores to non-users, but there were discordances among individual DASH dietary components. AH/LLD users tended towards higher calcium and sodium intakes. In a prior study, adherence to a low-density lipoprotein cholesterol (LDL)-lowering diet intervention was associated with a higher rate of discontinuing statin therapy, suggesting that adherent patients may have decided that dietary adherence obviated the need for medication..$^{27}$ Another recent study suggested that decisions for lifestyle modification were an often-cited rationale for failing to obtain prescribed medication,,$^{28}$ suggesting that patients may view lifestyle modifications and dietary restrictions as alternative strategies that reduce their need for medications. ${ }^{29}$

We also observed that the increased use of AHs/LLDs was associated with more obesity, cardiovascular disease and diabetes, findings which corroborate previous studies. Obesity is a risk factor for CAD) and stroke, but obesity is associated with better outcomes among patients 
with $\mathrm{CAD}$, which is known as the obesity paradox. ${ }^{30}$ Obesity paradox is questioned in that it is mainly due to unmeasured confounding of the relationship between a mediator variable and the outcome. ${ }^{31}$ Patients with obesity have increased use of AHs/LLDs, ${ }^{9}{ }^{32-35}$ and patients with CVD or diabetes have better adherence to statins. ${ }^{46}$ Perceptions of patients and physicians may affect adherence to AHs/LLDs. Patients with hypertension or hyperlipidaemia with additional risk factors such as diabetes or obesity might be more aware of their diagnosis and more likely to seek treatment with medications compared with patients with no risk factors. Individuals taking medications might also be more willing to change their lifestyle behaviours towards healthier choices. In ambulatory clinics in the USA, awareness of cardiovascular risk factors such as obesity or diabetes was positively associated with healthy behaviour. ${ }^{37}$ Patients with obesity and risk factors may be more frequently engaged in regular medical care and increased AH/LLD use may result. In a study of randomly sampled white Medicare beneficiaries, the non-obese group contained more current smokers, and more moderate and high alcohol consumers, compared with obese persons. ${ }^{38}$ The health concerns of patients with obesity may increase their acceptance of preventive medications. Physicians may selectively prescribe preventive medications in patients with obesity or cardiovascular disease, in accordance with therapeutic guidelines. ${ }^{35}$

Several limitations in this study are worth discussing. The true prevalence of hypertension and hyperlipidaemia or secondary prevention indications for LLDs could have been underestimated by self-reporting, as could the use of medication, with subsequent misclassification of users and non-users. However, our conclusions in this population-based study were maintained within analyses of the subjects with and without these conditions, which suggests internal and external validity of our analyses. Assessment of dietary intakes with two-hour dietary recalls could be imprecise, and subject to recall bias, if medication users recall their dietary status more reliably due to greater involvement in health maintenance. Some degree of non-differential misclassification bias or recall bias (a type of differential misclassification bias) due to imprecise or biased recall/self-report exists in any studies relying on self-report for variable measurement. However, we did not observe clinically significant differences in nutrient intake between users and non-users, except for higher magnesium intakes in users.

Because of the cross-sectional nature of the present study, we were not able to assess the causal relationship. A fear of serious cardiovascular disease such as stroke or myocardial disease in AH/LLD users rather than healthy lifestyle itself could have led them improve their behaviours. It is also possible that medication use influences dietary choices. Our data assess associations but not causal relationships between dietary choices and drug use, so we cannot rule out the possibility that medication use influences dietary choices. If non-users preferentially followed dietary modifications (as an alternative to medication) and users perceived AH/LLD use as an alternative to optimal dietary choices, our ability to detect a difference in dietary factors between the two groups could be compromised.

In conclusion, AH/LLD use was associated with several favourable socioeconomic and healthy lifestyle factors. The healthy user bias that distorts observational studies of AH/LLD effectiveness may be partly explained by unmeasured healthier lifestyle attributes or socioeconomic factors among medication users.

\section{Author affiliations}

'Department of Internal Medicine, Okinawa Chubu Hospital, Okinawa, Japan ${ }^{2}$ Institute of Clinical Pharmacy and Pharmaceutical Sciences, National Cheng Kung University, Tainan, Taiwan

3Department of Pharmacology, Drug Development and Therapeutics, University of Turku, Turku, Finland

${ }^{4}$ Department of Nephrology, Tufts Medical Center, Boston, USA

${ }^{5}$ Duke Clinical Research Institute, School of Medicine, Duke University, Durham, USA

Contributors All authors had access to the data and a role in writing the manuscript.

Competing interests None declared.

Provenance and peer review Not commissioned; externally peer reviewed.

Open Access This is an Open Access article distributed in accordance with the Creative Commons Attribution Non Commercial (CC BY-NC 4.0) license, which permits others to distribute, remix, adapt, build upon this work non-commercially, and license their derivative works on different terms, provided the original work is properly cited and the use is non-commercial. See: http://creativecommons.org/ licenses/by-nc/4.0

(c) Article author(s) (or their employer(s) unless otherwise stated in the text of the article) 2017. All rights reserved. No commercial use is permitted unless otherwise expressly granted.

\section{REFERENCES}

1. Bairey Merz CN, Alberts MJ, Balady GJ, et al. ACCF/AHA/ ACP 2009 competence and training statement: a curriculum on prevention of cardiovascular disease: a report of the American College of Cardiology Foundation/American Heart Association/ American College of Physicians Task Force on Competence and Training (Writing Committee to Develop a Competence and Training Statement on Prevention of Cardiovascular Disease): developed in collaboration with the American Academy of Neurology; American Association of Cardiovascular and Pulmonary Rehabilitation; American College of Preventive Medicine; American College of Sports Medicine; American Diabetes Association; American Society of Hypertension; Association of Black Cardiologists: Centers for Disease Control and Prevention; National Heart, Lung, and Blood Institute; National Lipid Association; and Preventive Cardiovascular Nurses Association. Circulation 2009;120:e100-e26.

2. Wright JM, Musini VM. First-line drugs for hypertension. Cochrane Database of Syst Rev 2009;8:CD001841.

3. Taylor F, Huffman MD, Macedo AF, et al. Statins for the primary prevention of cardiovascular disease. Cochrane Database of Syst Rev 2013;1:CD004816.

4. Mauskop A, Borden WB. Predictors of statin adherence. Curr Cardiol Rep 2011;13:553-8.

5. Mann DM, Woodward M, Muntner P, et al. Predictors of nonadherence to statins: a systematic review and meta-analysis. Ann Pharmacother 2010;44:1410-21.

6. Chapman RH, Benner JS, Petrilla AA, et al. Predictors of adherence with antihypertensive and lipid-lowering therapy. Arch Intern Med 2005;165:1147-52.

7. Glynn RJ, Knight EL, Levin R, et al. Paradoxical relations of drug treatment with mortality in older persons. Epidemiology 2001;12:682-9. 
8. Turnbull F, Neal B, Ninomiya T, et al; Blood Pressure Lowering Treatment Trialists' Collaboration. Effects of different regimens to lower blood pressure on major cardiovascular events in older and younger adults: meta-analysis of randomised trials. BMJ 2008;336:1121-3.

9. Mazzaglia G, Ambrosioni E, Alacqua M, et al. Adherence to antihypertensive medications and cardiovascular morbidity among newly diagnosed hypertensive patients. Circulation 2009;120:1598-605.

10. LaFleur J, Nelson RE, Sauer BC, et al. Overestimation of the effects of adherence on outcomes: a case study in healthy user bias and hypertension. Heart 2011;97:1862-9.

11. Setoguchi S, Warner Stevenson L, Stewart GC, et al. Influence of healthy candidate bias in assessing clinical effectiveness for implantable cardioverter-defibrillators: cohort study of older patients with heart failure. BMJ 2014;348:g2866.

12. Brookhart MA, Patrick AR, Dormuth $C$, et al. Adherence to lipidlowering therapy and the use of preventive health services: an investigation of the healthy user effect. Am J Epidemiol 2007; 166:348-54.

13. Lichtenstein AH, Appel LJ, Brands M, et al; American Heart Association Nutrition Committee. Diet and lifestyle recommendations revision 2006: a scientific statement from the american Heart Association Nutrition Committee. Circulation 2006;114:82-96.

14. Chiuve SE, McCullough ML, Sacks FM, et al. Healthy lifestyle factors in the primary prevention of coronary heart disease among men: benefits among users and nonusers of lipid-lowering and antihypertensive medications. Circulation 2006;114:160-7.

15. Dehghan M, Mente A, Teo KK, et al; Ongoing Telmisartan Alone and in Combination With Ramipril Global End Point Trial (ONTARGET)/Telmisartan Randomized Assessment Study in ACEI Intolerant Subjects With Cardiovascular Disease (TRANSCEND) Trial Investigators. Relationship between healthy diet and risk of cardiovascular disease among patients on drug therapies for secondary prevention: a prospective cohort study of 31546 high-risk individuals from 40 countries. Circulation 2012;126:2705-12.

16. Spatz ES, Ross JS, Desai MM, et al. Beyond insurance coverage: usual source of care in the treatment of hypertension and hypercholesterolemia. data from the 2003-2006 national Health and Nutrition Examination Survey. Am Heart J 2010;160:115-21.

17. Stone NJ, Robinson JG, Lichtenstein AH, et al; American College of Cardiology/American Heart Association Task Force on Practice Guidelines. 2013 ACC/AHA guideline on the treatment of blood cholesterol to reduce atherosclerotic cardiovascular risk in adults: a report of the American College of Cardiology/American Heart Association Task Force on Practice Guidelines. Circulation 2014;129:S1-S45.

18. Kuczmarski RJ, Ogden CL, Guo SS, et al. 2000 CDC growth charts for the United States: methods and development. Vital and health stat 11 2002:1-190.

19. Chasan-Taber S, Rimm EB, Stampfer MJ, et al. Reproducibility and validity of a self-administered physical activity questionnaire for male health professionals. Epidemiology 1996;7:81-6.

20. Mellen PB, Gao SK, Vitolins MZ, et al. Deteriorating dietary habits among adults with hypertension: DASH dietary accordance, NHANES 1988-1994 and 1999-2004. Arch Intern Med 2008;168:308-14.
21. Law MR, Cheng L, Dhalla IA, et al. The effect of cost on adherence to prescription medications in Canada. Can Med Assoc J 2012;184:297-302.

22. Rasmussen JN, Gislason GH, Rasmussen S, et al. Use of statins and beta-blockers after acute myocardial infarction according to income and education. J Epidemiol Community Health 2007;61:1091-7.

23. Selmer R, Sakshaug S, Skurtveit S, et al. Statin treatment in a cohor of 20212 men and women in Norway according to cardiovascular risk factors and level of education. Br J Clin Pharmacol 2009;67:355-62.

24. Aggarwal B, Mosca L. Lifestyle and psychosocial risk factors predict non-adherence to medication. Ann Behav Med 2010;40:228-33.

25. Kiortsis DN, Giral P, Bruckert E, et al. Factors associated with low compliance with lipid-lowering drugs in hyperlipidemic patients. J Clin Pharm Ther 2000;25:445-51.

26. Natarajan N, Putnam RW, Yip AM, et al. Family practice patients' adherence to statin medications. Can Fam Physician 2007:53:2144-5

27. Eussen SR, de Jong N, Rompelberg CJ, et al. Effects of the use of phytosterol/-stanol-enriched margarines on adherence to statin therapy. Pharmacoepidemiol Drug Saf 2010;19:1225-32.

28. Harrison TN, Derose SF, Cheetham TC, et al. Primary nonadherence to statin therapy: patients' perceptions. Am J Manag Care 2013;19:e133-9.

29. Maningat P, Gordon BR, Breslow JL. How do we improve patient compliance and adherence to long-term statin therapy? Curr Atheroscler Rep 2013;15:291.

30. Doehner W. Critical appraisal of the obesity paradox in cardiovascular disease: how to manage patients with overweight in heart failure? Heart Fail Rev 2014;19:637-44.

31. Banack HR, Kaufman JS. Does selection bias explain the obesity paradox among individuals with cardiovascular disease? Ann Epidemiol 2015;25:342-9.

32. Molenaar EA, Hwang SJ, Vasan RS, et al. Burden and rates of treatment and control of cardiovascular disease risk factors in obesity: the Framingham Heart Study. Diabetes Care 2008;31:1367-72.

33. Berthold HK, Gouni-Berthold I, Böhm M, et al. Patterns and predictors of statin prescription in patients with type 2 diabetes. Cardiovasc Diabetol 2009;8:25.

34. Rückert IM, Maier W, Mielck A, et al. Personal attributes that influence the adequate management of hypertension and dyslipidemia in patients with type 2 diabetes. Results from the DIAB-CORE Cooperation. Cardiovasc Diabetol 2012;11:120.

35. Steinberg BA, Cannon CP, Hernandez AF, et al. Medical therapies and invasive treatments for coronary artery disease by body mass: the "obesity paradox" in the Get With The Guidelines database. Am J Cardiol 2007;100:1331-5.

36. Grigoryan L, Pavlik VN, Hyman DJ. Predictors of antihypertensive medication adherence in two urban health-care systems. Am J Hypertens 2012;25:735-8.

37. Alzaman N, Wartak SA, Friderici J, et al. Effect of patients awareness of CVD risk factors on health-related behaviors. South Med J 2013;106:606-9.

38. Koster A, Penninx BW, Newman AB, et al. Lifestyle factors and incident mobility limitation in obese and non-obese older adults. Obesity 2007;15:3122-32. 